\title{
Synthesis and characterization of mullite-zirconia composites by reaction sintering of zircon flour and sillimanite beach sand
}

\author{
P KUMAR, M NATH, A GHOSH and H S TRIPATHI* \\ Refractories Division, CSIR - Central Glass \& Ceramic Research Institute, 196 Raja S.C. Mullick Road, \\ Jadavpur, Kolkata 700 032, India
}

MS received 23 April 2014; accepted 28 October 2015

\begin{abstract}
Mullite-zirconia composites containing 10-30 wt\% zirconia were prepared by reaction sintering of zircon flour, sillimanite beach sand and calcined alumina. Raw materials were attrition milled, shaped into pellets and bars and sintered in the temperature range of $1450-1600^{\circ} \mathrm{C}$ with $2 \mathrm{~h}$ soaking at peak temperature. Sintered products were analysed in terms of various physical, mechanical and thermo-mechanical properties. The analyses of phases developed and microstructural analyses were carried out by X-ray diffraction (XRD) and scanning electron microscope (SEM), respectively. It was observed that the addition of $\mathrm{ZrO}_{2}$ up to $20 \mathrm{wt} \%$ significantly improves flexural strength and fracture toughness. The transformation of $\mathbf{t} \rightarrow \mathrm{m}$ zirconia was found to be the dominant mechanism for enhancement in mechanical properties. $\mathrm{ZrO}_{2}$ occupies both the intergranular as well as intragranular positions. However, intragranular zirconias are much smaller compared to intergranular zirconias.
\end{abstract}

Keywords. Mullite; zirconia; reaction sintering; mechanical properties; microstructure.

\section{Introduction}

Mullite is the only stable phase in the $\mathrm{Al}_{2} \mathrm{O}_{3}-\mathrm{SiO}_{2}$ binary phase system ${ }^{1}$ and has been able to attract the attention of researchers because of its unique properties like high melting point, low coefficient of thermal expansion, high creep resistance, chemical resistance and hardness, which makes it a favourable material for high-temperature structural applications. ${ }^{2,3}$ However, lower fracture toughness and mechanical strength limit its use. Various investigators have worked to enhance the mechanical properties of mullite and found that the incorporation of zirconia in mullite matrix improves its mechanical properties either by transformation toughening mechanism ${ }^{4-6}$ or micro-cracking. ${ }^{7}$

Different processing techniques have been developed to synthesize mullite-zirconia composites such as sol-gel processing, ${ }^{8,9}$ co-precipitation ${ }^{10,11}$ and reaction sintering. ${ }^{12-18}$ Out of all these routes, reaction sintering is an economical, simple and only process in which natural zircon can be used directly to develop mullite-zirconia composites. In this process, reactions among the starting materials and densification can be accomplished simultaneously in a single heat treatment process. The drawback of this process is that, it is difficult to control because of the competition between the reactions and densification, ${ }^{19}$ which may lead to incomplete reactions or poor densification.

Researchers have always keen interest in the field of good quality raw materials. However, high consumption of natural resources over the years leaves subsequent depletion of

\footnotetext{
*Author for correspondence (hstripathi@cgcri.res.in)
}

high-quality resources, hence, it is necessary to explore the alternate and ample available raw materials, which can be used to continue the production of such composites. India is one of the countries which have abundant deposits of beach sand containing rare earth compounds. After the extraction of rare earth compounds, a huge amount of beach sand sillimanite and zircon sand are obtained as by-products. ${ }^{20}$ Works have been carried out to convert sillimanite beach sand into mullite. ${ }^{21-23}$ Haldar and Banerjee ${ }^{24}$ have prepared mullite-zirconia composites from beach sand sillimanite, zirconia and alumina. Also some investigators have synthesized mullite-zirconia composites by reaction sintering of zircon flour and alumina. ${ }^{25,26}$ However, very little work has been carried out to synthesize such composites using both zircon sand and sillimanite sand.

In the present study, mullite-zirconia composites have been prepared by the reaction sintering of zircon flour and sillimanite sand. Calcined alumina has been added to maintain proper stoichiometry of mullite. The zircon flour reacts with sillimanite and calcined alumina according to the following reaction:

$$
\begin{gathered}
x \mathrm{ZrSiO}_{4}+x \mathrm{Al}_{2} \mathrm{O}_{3} \cdot \mathrm{SiO}_{2}+2 x \mathrm{Al}_{2} \mathrm{O}_{3} \rightarrow 3 x \mathrm{Al}_{2} \mathrm{O}_{3} . \\
2 x \mathrm{SiO}_{2}+x \mathrm{ZrO}_{2} .
\end{gathered}
$$

Resulting composites have been characterized in terms of various mechanical and thermo-mechanical properties.

\section{Experimental}

Raw materials used in this investigation were zircon flour (obtained from zircon beach sand, supplied by Indian Rare 
Earth Limited, Bombay, India), sillimanite sand (Trimax Industries, India) and calcined alumina (SG grade, Hindalco, India). All the raw materials were characterized in terms of physico-chemical properties. Chemical analyses were carried out by standard wet chemical methods. Three batch compositions were prepared containing 10, 20 and $30 \mathrm{wt} \%$ of zirconia (table 1). Raw materials were mixed and grounded by attrition milling in ethanol medium using zirconia pot and zirconia grinding media for $4 \mathrm{~h}$ at the speed of 400 RPM. Resulting slurries thus obtained were initially air dried followed by drying at a temperature of $100 \pm 5^{\circ} \mathrm{C}$ for $24 \mathrm{~h}$. Dried materials were then crushed and passed through 100 mesh sieve to get the desired powder. Powders were uniformly mixed with 5\% PVA solution as binder and shaped into bars $($ size $75 \times 5 \times 5 \mathrm{~mm})$ and pellets (size $\varnothing 20 \times 10 \mathrm{~mm})$ by uniaxially pressing at $45 \mathrm{MPa}$ followed by the cold isostatic pressing at $140 \mathrm{MPa}$. Pressed samples were dried for $24 \mathrm{~h}$ in air oven at a temperature of $100 \pm 5^{\circ} \mathrm{C}$ after $24 \mathrm{~h}$ natural drying. The dried samples were sintered in the temperature range of $1450-1600^{\circ} \mathrm{C}$ in the interval of $50^{\circ} \mathrm{C}$ with $2 \mathrm{~h}$ soaking at peak temperature in oxidizing atmosphere at normal pressure.

Firing was carried out in programme controlled electric furnace and heating rate was maintained at $5^{\circ} \mathrm{C} \mathrm{min}^{-1}$ from

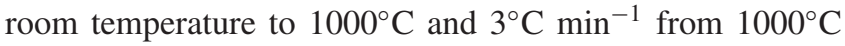
to final temperature followed by natural cooling to ambient temperature. Sintered samples thus produced were characterized in terms of various physical, mechanical and thermomechanical properties. Bulk density and apparent porosity of the samples were measured by the conventional water

Table 1. Batch compositions with codes.

\begin{tabular}{lccc}
\hline Sample codes & $\begin{array}{c}\text { Zircon flour } \\
\text { (wt\%) }\end{array}$ & $\begin{array}{c}\text { Sillimanite } \\
(\mathrm{wt} \%)\end{array}$ & $\begin{array}{c}\text { Calcined alumina } \\
\text { (wt\%) }\end{array}$ \\
\hline $1 \mathrm{Z}$ & 16.54 & 50.84 & 32.61 \\
$2 \mathrm{Z}$ & 33.09 & 29.98 & 36.92 \\
$3 \mathrm{Z}$ & 49.66 & 9.13 & 41.21 \\
\hline
\end{tabular}

displacement method using Archimedes' principle. Phase identification was carried out by the X-ray diffraction (XRD) technique. XRD pattern of samples were taken by Philips $\mathrm{X}$-ray diffractometer (model PW 1730) using nickel filtered $\mathrm{Cu}-\mathrm{K} \alpha$ radiation, and diffraction patterns were recorded over Braggs' angle $(2 \theta)$ range of $10-80^{\circ}$. To avoid the conversion of tetragonal to monoclinic zirconia during powder formation, bulk samples of the size $\varnothing 20 \times 2 \mathrm{~mm}$ were used for XRD. Phase analysis of zirconia was carried out by using the formula developed by Garvie and Nicolson. ${ }^{27}$ IR transmission spectra were taken by Perkin-Elmer spectrophotometer in the range of $1000-400 \mathrm{~cm}^{-1}$ (finger print region), because, most of the characteristics IR frequencies of $\mathrm{M}-\mathrm{O}$ (metal-oxygen) bond lie in the region $<1000 \mathrm{~cm}^{-1}$. Thermal expansion of the sintered bar samples (dimension $25 \times 5 \times 5 \mathrm{~mm}$ ) were performed on Dilatometer (model no. NETZSCH DIL 402C). The flexural strength at room temperature was determined by three-point bending method (with a span of $40 \mathrm{~mm}$ and cross-head speed of $0.5 \mathrm{~mm}$ $\min ^{-1}$ ) using Universal Testing Machines (model no. Instron 5500R). Flexural strength at elevated temperatures $(600,900$ and $1200^{\circ} \mathrm{C}$ ) was also measured by the three-point bending method. Microstructural characterization was performed on the polished and thermally etched samples by scanning electron microscopy (SEM) (Supra ${ }^{\mathrm{TM}}$ 35VP, Carl Zeiss) after carbon coating. Hardness and fracture toughness of the samples were measured by Vickers' indentation method ${ }^{28}$ by applying $3 \mathrm{kgf}$ load with $15 \mathrm{~s}$ dwell time on polished surface.

\section{Results and discussions}

The physico-chemical properties of the raw materials are shown in table 2. Zircon flour contains 59.74\% $\mathrm{ZrO}_{2}$ and $31.94 \% \mathrm{SiO}_{2}$ as its major constituents. $\mathrm{Al}_{2} \mathrm{O}_{3}$ and $\mathrm{CaO}$ are the main impurities present in zircon flour. $\mathrm{Al}_{2} \mathrm{O}_{3}$ content in sillimanite is $59.87 \%$ compared to the theoretical value of $62.92 \%$. The extra silica in sillimanite exist as free quartz, which is further confirmed from XRD pattern. Specific

Table 2. Physico-chemical properties of raw materials.

\begin{tabular}{lccc}
\hline Properties & Zircon flour & Sillimanite & Calcined alumina \\
\hline Chemical constituents (wt\%) & & & \\
$\mathrm{ZrO}_{2}$ & 59.74 & - & - \\
$\mathrm{SiO}_{2}$ & 31.94 & 38.57 & 0.017 \\
$\mathrm{Al}_{2} \mathrm{O}_{3}$ & 6.76 & 59.87 & 99.54 \\
$\mathrm{Fe}_{2} \mathrm{O}_{3}$ & 0.17 & 0.40 & 0.017 \\
$\mathrm{TiO}_{2}$ & Trace & 0.07 & - \\
$\mathrm{HfO}_{2}$ & 0.03 & - & - \\
$\mathrm{CaO}$ & 1.03 & - & - \\
$\mathrm{MgO}$ & Trace & - & - \\
$\mathrm{K}_{2} \mathrm{O}$ & Trace & 0.09 & 0.4 \\
$\mathrm{Na} 2 \mathrm{O}$ & 0.07 & 0.40 & Corundum \\
$\mathrm{Major}$ crystalline phases & Zircon & Sillimanite & 3.97 \\
$\mathrm{Specific}$ gravity & 4.60 & 3.22 & - \\
\hline
\end{tabular}


gravity of calcined alumina is 3.97 , which is very close to specific gravity of pure alumina. In sillimanite and calcined alumina, $\mathrm{Fe}_{2} \mathrm{O}_{3}$ and $\mathrm{Na}_{2} \mathrm{O}$ are found as major impurities. XRD patterns of raw materials are given in figure 1 . In zircon flour major phase is identified as zircon [PDF no. 081-0588]. Sillimanite [PDF no. 038-0471] is appeared as major phase with small amount of quartz in sillimanite beach sand and calcined alumina contains only corundum [PDF no. 050-1496] as its crystalline phase.

\subsection{Densification}

Densification is measured by the decrease in apparent porosity and the increase in bulk density. Variation of apparent porosity and bulk density of samples with the sintering temperature are shown in figure 2. Bulk density continuously increases with the increase in sintering temperature due to gradual removal of pores and almost nil apparent porosity

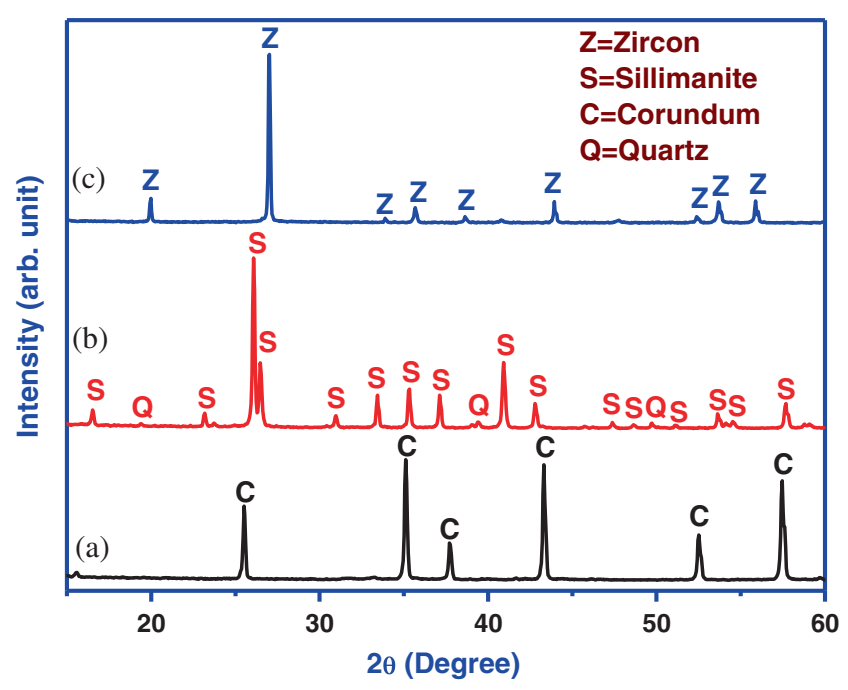

Figure 1. XRD patterns of raw materials: (a) calcined alumina, (b) sillimanite sand and (c) zircon flour.

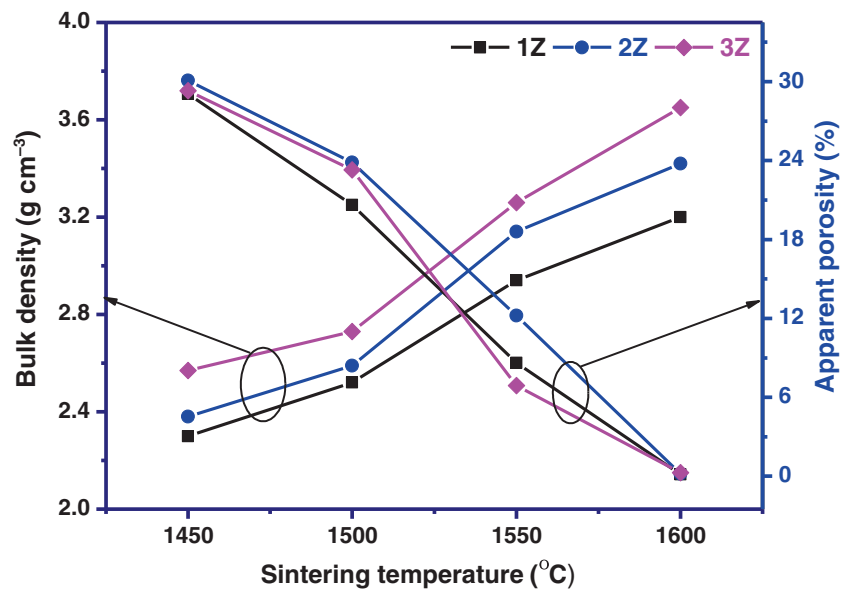

Figure 2. Variation of bulk density and apparent porosity of sintered samples with zirconia content and sintering temperature.
$(<1 \%)$ has been reached at $1600^{\circ} \mathrm{C}$. Bulk density of the samples $1 \mathrm{Z}, 2 \mathrm{Z}$ and $3 \mathrm{Z}$ are $2.30,2.38$ and $2.57 \mathrm{~g} \mathrm{~cm}^{-3}$ at $1450^{\circ} \mathrm{C}$, which increases to $3.20,3.42$ and $3.65 \mathrm{~g} \mathrm{~cm}^{-3}$ at $1600^{\circ} \mathrm{C}$, respectively. Similarly, apparent porosity of the samples was around $30 \%$ at the temperature $1450^{\circ} \mathrm{C}$, which reduces to almost nil at $1600^{\circ} \mathrm{C}$. At the same temperature, bulk densities of the samples increases with the increase in zirconia content because of the higher true density of zirconia relative to mullite. Relative density of the samples against the sintering temperature is plotted in figure 3 . It can be seen that at temperature $1450^{\circ} \mathrm{C}$, around $66 \%$ of the theoretical density has been achieved which has increased to more than $98 \%$ at $1600^{\circ} \mathrm{C}$.

\subsection{XRD and IR analysis}

XRD pattern of the sample 2Z (containing $20 \%$ zirconia) sintered at temperatures 1500,1550 and $1600^{\circ} \mathrm{C}$ is presented in figure 4 .

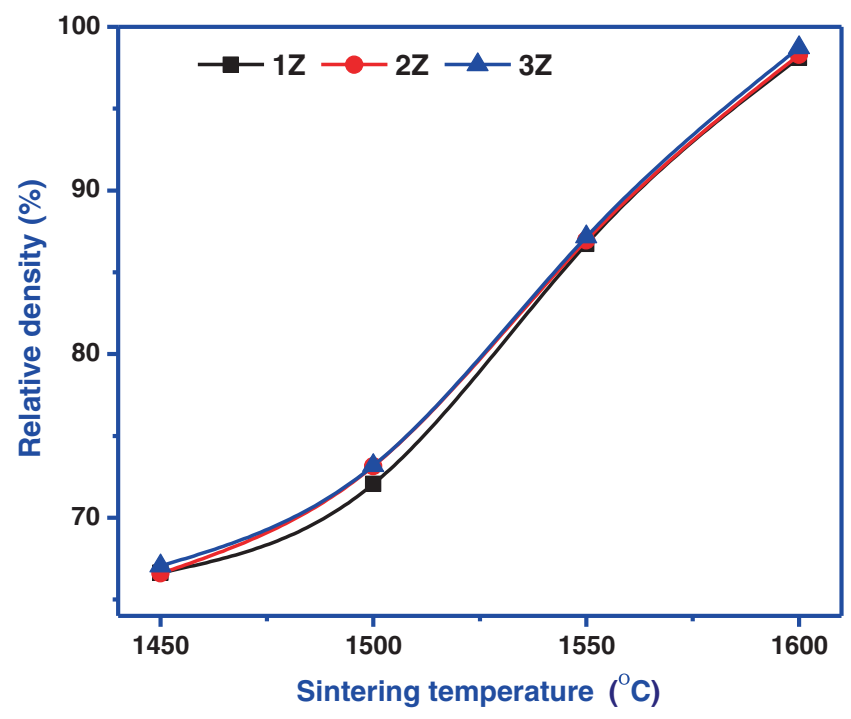

Figure 3. Variation of relative density of the samples with sintering temperature and zirconia content.

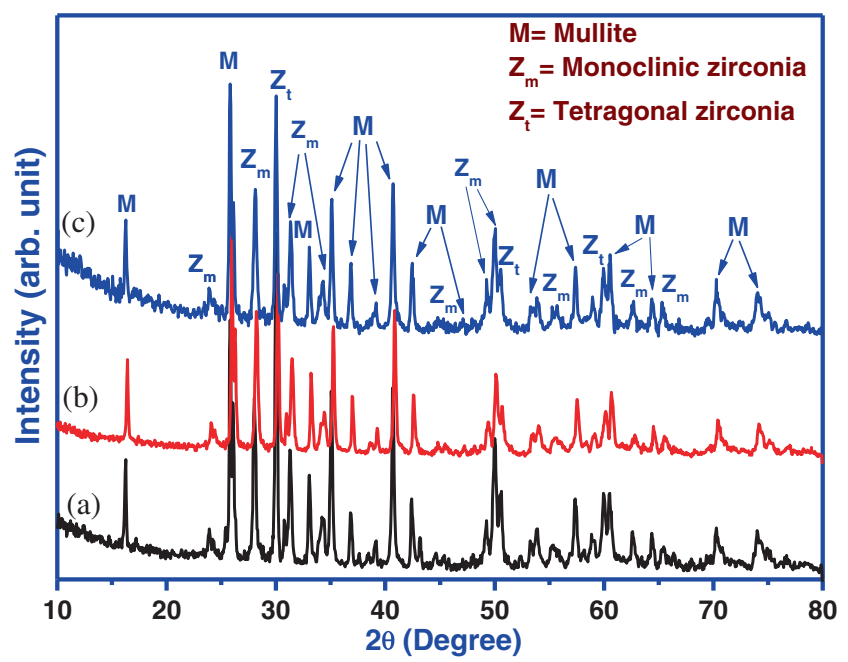

Figure 4. XRD pattern of sample $2 \mathrm{Z}$ sintered at different temperatures: (a) $1500^{\circ} \mathrm{C}$, (b) $1550^{\circ} \mathrm{C}$ and (c) $1600^{\circ} \mathrm{C}$. 
From XRD phase analysis, three major phases have been identified, viz., mullite (PDF no. 085-1460), tetragonal zirconia (PDF no. 079-1769) and monoclinic zirconia (PDF

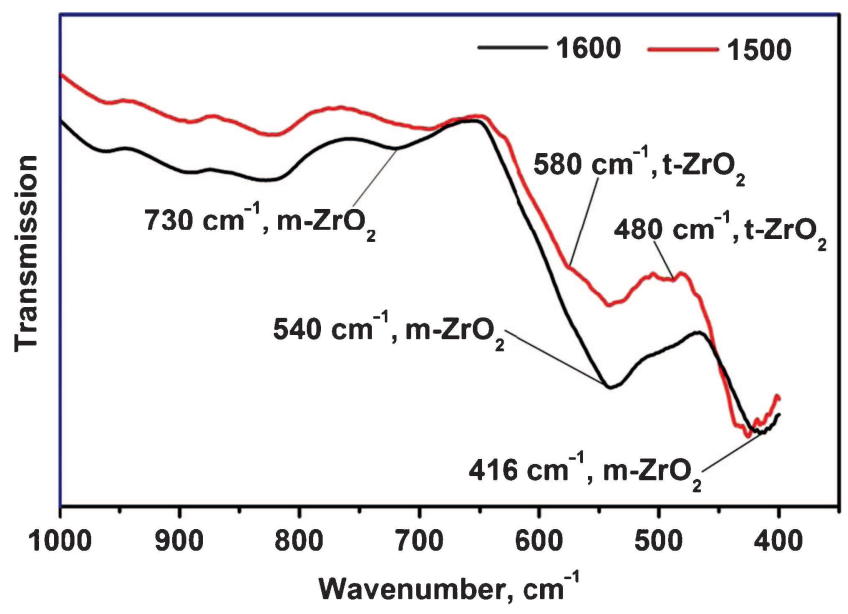

Figure 5. IR transmission spectra of samples $2 \mathrm{Z}$ sintered at 1500 and $1600^{\circ} \mathrm{C}$.

Table 3. Tetragonal content and different grain sizes of samples.

\begin{tabular}{lccllc}
\hline & \multicolumn{2}{c}{$\mathrm{t}$-Zirconia content $(\%)$} & & \multicolumn{2}{c}{ Grain size $(\mu \mathrm{m})$ at $1600^{\circ} \mathrm{C}$} \\
\cline { 2 - 3 } \cline { 5 - 6 } Samples & $1550^{\circ} \mathrm{C}$ & $1600^{\circ} \mathrm{C}$ & & Mullite & Zirconia \\
\hline $1 Z$ & 55.31 & 40.38 & & 3.19 & 1.49 \\
$2 Z$ & 43.21 & 37.33 & & 2.32 & 1.60 \\
$3 Z$ & 30.25 & 25.46 & & 2.4 & 1.62 \\
\hline
\end{tabular}

no. 037-1484). No extra peaks have appeared in this temperature range, which shows that the complete reactions among the starting materials have taken place and mullite-zirconia composites have formed.

IR transmission spectra of the sample $2 \mathrm{Z}$ sintered at 1500 and $1600^{\circ} \mathrm{C}$ are shown in figure 5. The sample sintered at $1500^{\circ} \mathrm{C}$ shows two $\mathrm{t}-\mathrm{ZrO}_{2}$ peaks at around 480 and 580 $\mathrm{cm}^{-1}$, which are diminished at $1600^{\circ} \mathrm{C}$. Also, $\mathrm{m}-\mathrm{ZrO}_{2}$ peaks correspond to $730,540,416 \mathrm{~cm}^{-129}$ and are relatively more intense for the samples sintered at $1600^{\circ} \mathrm{C}$. This shows that with the increase in sintering temperature, the relative tetragonal content of the samples has decreased, which is further quantified by XRD.

Quantitative phase analysis of the samples sintered at 1550 and $1600^{\circ} \mathrm{C}$ is shown in table 3. Although no stabilizer has been used, higher amount of tetragonal zirconia is found in the samples. This is mainly because of the presence of impurities like $\mathrm{CaO}$ in zircon flour, which stabilizes the tetragonal zirconia phase. As the sintering temperature are increased from 1550 to $1600^{\circ} \mathrm{C}$, it is found that tetragonal content of zirconia decreases (table 3). This is mainly due to increase in grain size with sintering temperature. Lower grain size contains higher amount of tetragonal zirconia and larger grains have higher monoclinic zirconia. ${ }^{30}$

\subsection{Microstructures}

Scanning electron photomicrographs of the samples fired at $1600^{\circ} \mathrm{C}$ are shown in figure 6. It reveals that almost dense mullite-zirconia composites are formed at $1600^{\circ} \mathrm{C}$,
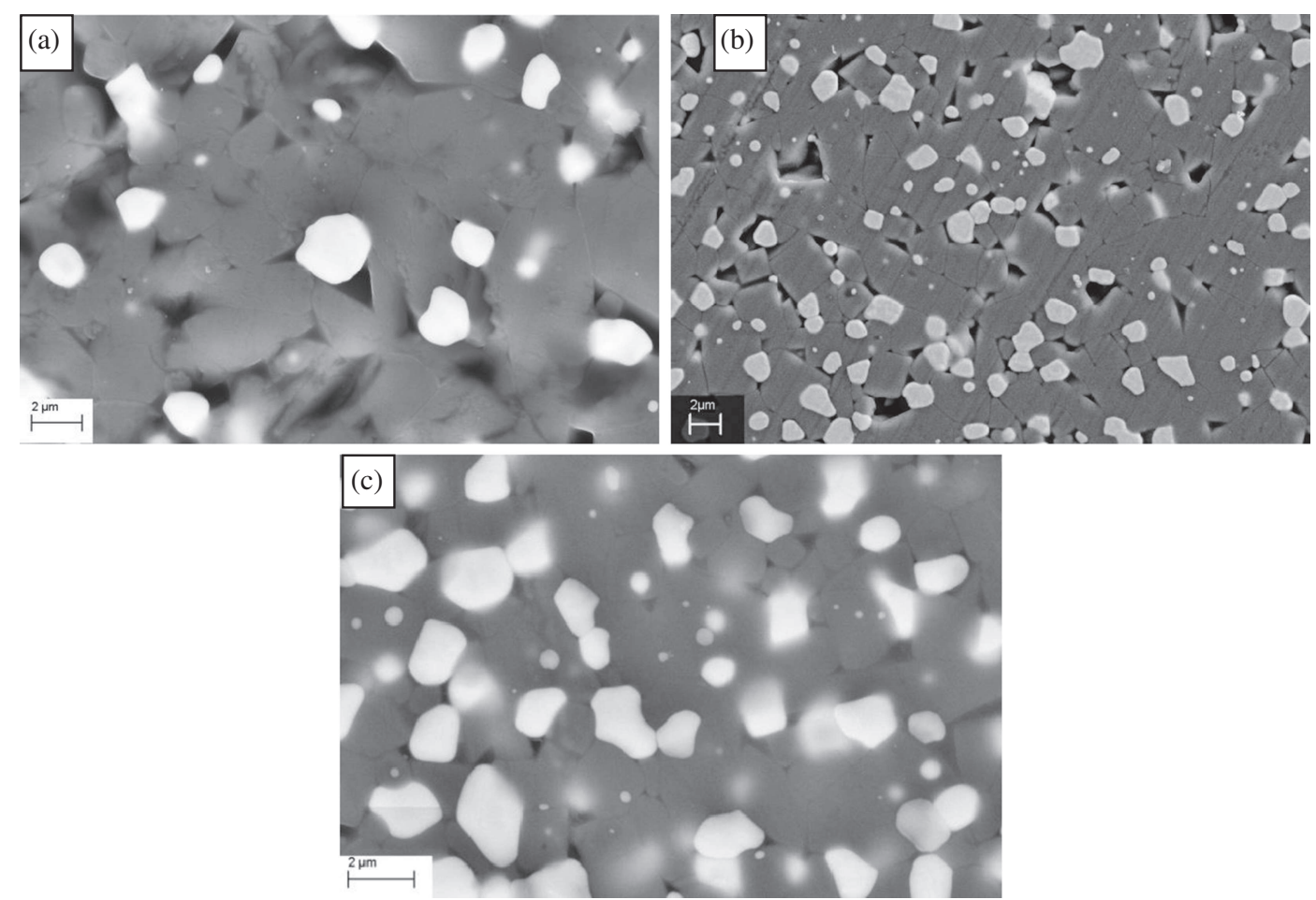

Figure 6. SEM photomicrographs of the samples fired at $1600^{\circ} \mathrm{C}$ : (a) $1 \mathrm{Z}$, (b) $2 \mathrm{Z}$ and (c) $3 \mathrm{Z}$. 
although some closed pores are present. Two main phases have appeared, viz., mullite (dark grains) and zirconia (bright grains). Mullite grains are equiaxed in nature, but also some elongated grains have developed. Zirconia grains have occupied the intergranular as well as intragranular positions in mullite matrix. The average grain size of mullite and zirconia in different samples is summarized in table 3. Mullite grain size decreases with the increase in zirconia content, which shows that the incorporation of zirconia reduces the grain growth of mullite. ${ }^{31}$

\subsection{Mechanical and thermo-mechanical properties}

Flexural strength of the samples at room temperature as well as elevated temperatures is shown in figure 7. Flexural strength initially decreases till $900^{\circ} \mathrm{C}$, later it shows increasing trend. Initial drop in flexural strength is because of the elastic bond relaxation between the molecules ${ }^{32}$ and as the temperature crosses this value, it starts increasing. Increment in flexural strength after $900^{\circ} \mathrm{C}$ is due to healing up the critical flaws by the highly viscous glassy phases, which form at higher temperatures. ${ }^{33}$

Coefficient of linear expansion of samples is shown in table 4. Sample 3Z shows much lower coefficient of linear expansion mainly because of the lower amount of tetragonal

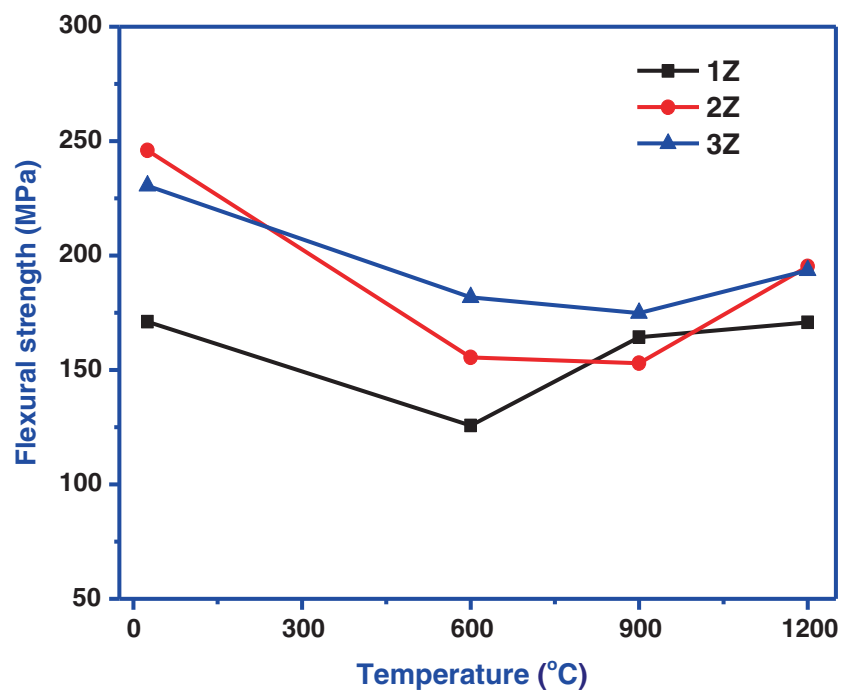

Figure 7. Variation of flexural strength of the samples sintered at $1600^{\circ} \mathrm{C}$ with temperature.

Table 4. Thermal properties of different samples sintered at $1600^{\circ} \mathrm{C}$.

\begin{tabular}{lc}
\hline Sample & $\begin{array}{c}\text { Coefficient of thermal } \\
\text { expansion } \alpha, \text { in } \times 10^{-6}{ }^{\circ} \mathrm{C}^{-1} \\
\left(30-1400^{\circ} \mathrm{C}\right)\end{array}$ \\
\hline $1 \mathrm{Z}$ & 6.01 \\
$2 \mathrm{Z}$ & 5.97 \\
$3 \mathrm{Z}$ & 4.73 \\
\hline
\end{tabular}

content (table 3 ). Higher the tetragonal content, higher is the coefficient of thermal expansion because of the high value of CTE of tetragonal phase $\left(\sim 11 \times 10^{-6}{ }^{\circ} \mathrm{C}^{-1}\right)$ compared to monoclinic zirconia $\left(\sim 7 \times 10^{-6}{ }^{\circ} \mathrm{C}^{-1}\right)$.

Variation of $\mathrm{t}-\mathrm{ZrO}_{2}$ and various mechanical properties at room temperature of different samples sintered at $1600^{\circ} \mathrm{C}$ against the addition of zirconia are illustrated in figure 8 . With the increase in amount of zirconia from 10 to $30 \mathrm{wt} \%$; retention of $\mathrm{t}-\mathrm{ZrO}_{2}$ reduces from 40.38 to $25 \%$. Higher zirconia containing samples shows more transformation from tetragonal to monoclinic zirconia during cooling. Transformation of $\mathrm{t} \rightarrow \mathrm{m} \mathrm{ZrO}_{2}$ causes around 5-6\% volume expansion, which is confined by mullite. With the increase in zirconia content, the amount of restricting phase (mullite) decreases. So, the transformation of tetragonal to monoclinic during cooling is increased with the increase in zirconia content.

Flexural strength of the samples containing 10, 20 and $30 \%$ zirconia are 171.7, 245.8 and $230.4 \mathrm{MPa}$, respectively. It can be observed that up to $20 \%$ incorporation of zirconia in mullite matrix substantially improves its flexural strength, while further addition of zirconia decreases the flexural strength. However, fracture toughness of the samples increases with the increase in zirconia content. Samples

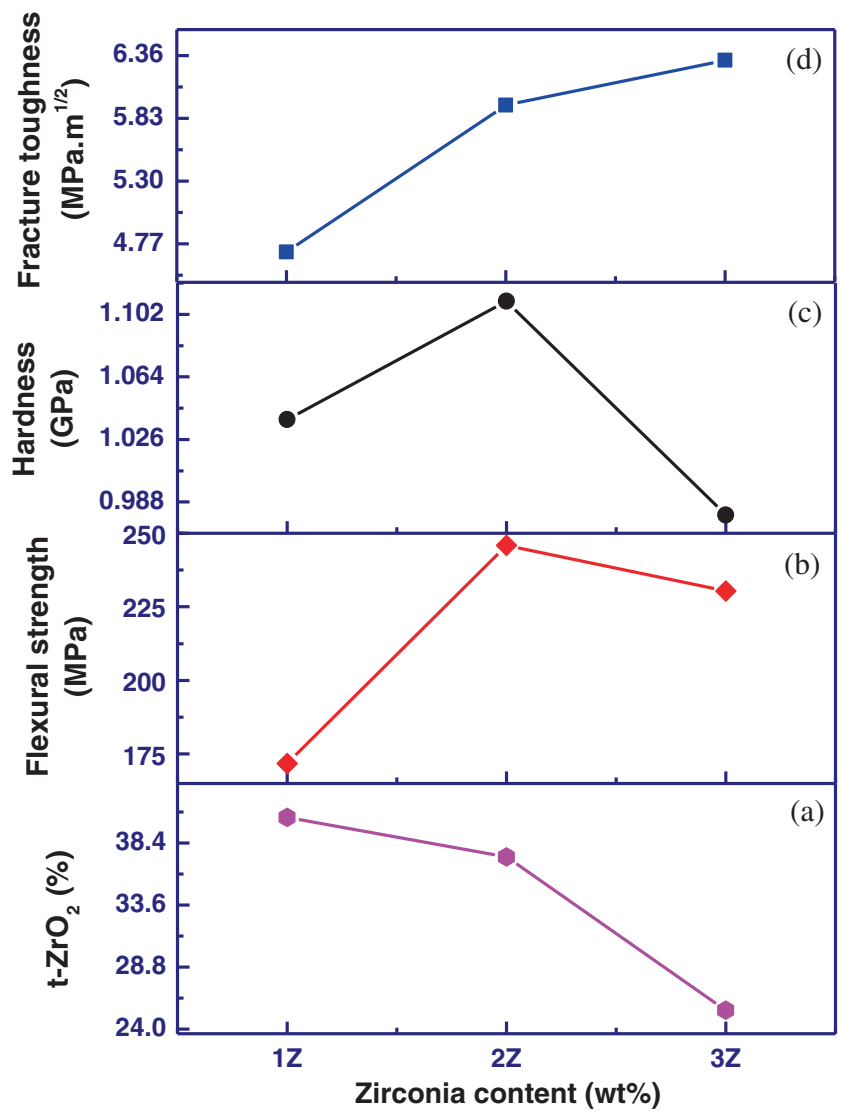

Figure 8. Variation of $\mathrm{t}-\mathrm{ZrO}_{2}$ and various mechanical properties at room temperature of different samples sintered at $1600^{\circ} \mathrm{C}$ with zirconia content: (a) $\mathrm{t}-\mathrm{ZrO}_{2}$, (b) flexural strength, (c) hardness and (d) fracture toughness. 
containing 10\% zirconia (1Z) have fracture toughness 4.70 $\mathrm{MPa} \mathrm{m}^{1 / 2}$ which increases to 5.94 and $6.32 \mathrm{MPa} \mathrm{m}^{1 / 2}$ after the addition of $20 \%$ (2Z) and $30 \%$ (3Z) of zirconia, respectively. Hardness of the samples $1 \mathrm{Z}, 2 \mathrm{Z}$ and $3 \mathrm{Z}$ has found to be $1.04,1.11$ and $0.98 \mathrm{GPa}$, respectively.

The addition of $\mathrm{ZrO}_{2}$ up to $20 \mathrm{wt} \%$ increases the hardness, flexural strength and fracture toughness. Further addition of $\mathrm{ZrO}_{2}$ increases the fracture toughness, but hardness and flexural strength decreases. Transformation of tetragonal to monoclinic zirconia creates micro-cracks, which improves the flexural strength and fracture toughness. However, if $\mathrm{t} \rightarrow \mathrm{m}$ transformation exceeds a certain value, it has negative impact on mechanical strength. ${ }^{34}$ For the samples containing $20 \mathrm{wt} \%$ zirconia, tetragonal to monoclinic transformation is around $62.67 \%$. This transformation $(\mathrm{t} \rightarrow \mathrm{m})$ creates microcracks, which increases the flexural strength and fracture toughness. However, in samples containing $30 \mathrm{wt} \% \mathrm{ZrO}_{2}$, fractional content of monoclinic zirconia is around $75 \%$, which generate macro-cracks that reduces flexural strength of the samples.

\section{Conclusions}

Nearly dense mullite-zirconia composites were prepared by the reaction sintering of zircon-flour, sillimanite and calcined alumina at temperature $1600^{\circ} \mathrm{C}$ with $2 \mathrm{~h}$ soaking time. It was found that the incorporation of zirconia in mullite matrix enhances its mechanical properties, especially flexural strength and fracture toughness. The addition of 10-20 wt $\%$ of zirconia substantially improved the flexural strength from 171.7 to $245.9 \mathrm{MPa}$ and fracture toughness from 4.70 to $5.94 \mathrm{MPa} \mathrm{m}^{1 / 2}$ at room temperature. Further addition of zirconia from 20 to $30 \mathrm{wt} \%$ increases fracture toughness to $6.32 \mathrm{MPa} \mathrm{m} \mathrm{m}^{1 / 2}$ on the cost of decrement in flexural strength. The transformation of tetragonal to monoclinic zirconia was found to be prominent mechanism behind the enhancement of mechanical properties of zirconia-mullite composites.

\section{Acknowledgement}

We are grateful to the Director, CSIR-CG\&CRI, for the financial support and permission to publish this paper.

\section{References}

1. Aksay I A and Pask J A 1975 J. Am. Ceram. Soc. 58507

2. Lessing P A, Gordon R S and Mazdiyasni K S 1975 J. Am. Ceram. Soc. $\mathbf{5 8} 149$
3. Prochazka S, Wallace J S and Claussen N 1983 J. Am. Ceram. Soc. $66 \mathrm{c} 125$

4. McMeeking R M and Evans A C 1982 J. Am. Ceram. Soc. 65 242

5. Deportu G and Henney J W 1984 Br. Ceram. Trans. J. 8369

6. Chevalier J and Gremillard L 2009 J. Am. Ceram. Soc. 921901

7. Kreher W and Pompe W 1981 J. Mater. Sci. 16694

8. Yuan Q-M, Tan J-Q, Shen J-Y, Zhu X-H and Yang Z-F 1986 J. Am. Ceram. Soc. 69268

9. Wen-Cheng J, Kao H C and Lo M H 1996 J. Eur. Ceram. Soc. 16239

10. Kubota Y and Takagi H 1986 Proc. Br. Ceram. Soc. 37179

11. Rajendran S and Rossell H J 1991 J. Mater. Sci. 265815

12. Rupo E D, Carruthers T G and Brook R J 1978 J. Am. Ceram. Soc. 61468

13. Rupo E D, Cilbart E, Carruthers T G and Brook R J 1979 J. Mater. Sci. 14705

14. Claussen N and Jahn J 1980 J. Am. Ceram. Soc. 63228

15. Rupo E D and Anseau M R 1980 J. Mater. Sci. 15114

16. Yangyun S and Brook R J 1983 Ceram. Int. 939

17. Anseau M R, Leblud C and Cambier F 1983 J. Mater. Sci. Lett. 2366

18. Portu G D and Henney J W 1984 Trans. Br. Ceram. Soc. 8369

19. Boch P and Giry J P 1985 Mater. Sci. Eng. 7139

20. Banerjee G 1998 Bull. Mater. Sci. 21349

21. Tripathi H S and Banerjee G 1998 J. Eur. Ceram. Soc. 18 2081

22. Tripathi H S and Banerjee G 1999 Ceram. Int. 2519

23. Tripathi H S, Das S K and Banerjee G 2000 Ceram. Int. 261

24. Haldar K M and Banerjee G 2003 Mater. Lett. 573513

25. Das K, Mukherjee B and Banerjee G 1998 J. Eur. Ceram. Soc. 181771

26. Das K and Banerjee G 2000 J. Eur. Ceram. Soc. 20153

27. Garvie R C and Nicholson P S 1972 J. Am. Ceram. Soc. 55 303

28. Anstis G R, Chantikul P, Lawn B R and Marshall D B $1981 \mathrm{~J}$. Am. Ceram. Soc. 64533

29. Monte F, Larsen W and Mackenzie J D 2000 J. Am. Ceram. Soc. $\mathbf{8 3} 628$

30. Gupta T K, Bechtold J H, Kuznicki R C, Cadoff L H and Rossing B R 1977 J. Mater. Sci. 122421

31. Holmstrom M, Chartier T and Boch P 1989 Mater. Sci. Eng. A 109105

32. Osendi M I and Baudin C 1996 J. Eur. Ceram. Soc. 16217

33. Kumazawa T, Ohta S, Kanzaki S, Sakaguchi S and Tabata H 1989 J. Mater. Sci. Lett. 847

34. Sahnoune F and Saheb N 2010 EPJ web of conferences Vol. 6, 20005-p.1 